\title{
Effect of combined alcohol and tobacco exposure on risk of cancer of the hypopharynx
}

\author{
JØRN OLSEN, ${ }^{1,2}$ SVEND SABROE ${ }^{2}$ AND JOHANNES IPSEN ${ }^{2}$
}

From the Institute of Community Health, ${ }^{1}$ Department of Social Medicine, University of Odense, Denmark, and the Institute of Social Medicine, ${ }^{2}$ University of Aarhus, Vesterbro Torv 1 - 3, 8000 Aarhus C, Denmark

SUMmARY The effect of moderate to heavy exposure to alcohol and tobacco on the risk of cancer of the hypopharynx is estimated in a case-control study. All incident hypopharyngeal cancer patients in Denmark who were under 75 years of age were compared with incident cases of laryngeal cancer and population sampled controls. The ascertainment of cases and controls took place during March 1980 to March 1982. Thirty-two patients with cancer of the hypopharynx, 321 patients with cancer of the larynx, and 1141 population sampled controls participated in the study. The effect of combined exposure to alcohol and tobacco seemed to be multiplicative rather than additive, a finding which is similar to that in laryngeal cancer patients. However, as there were only small numbers, only major deviations from the additive or multiplicative model for interaction would be detectable.

The incidence of cancer of the hypopharynx is low in Denmark. As shown in the figure, cancer of the hypopharynx in Denmark is two to three times more common in males than in females. No apparent increase in the incidence rates since 1948 is seen, except for males in the period from 1973 to 1980 . This increase is due mainly to a more than doubling of the incidence rate in the age group 55-64 years. However, the rates are based on small numbers: only 153 female cancer patients and 362 male cancer patients were reported to the cancer registry from 1948 to 1980 . No hypopharyngeal cancer patient under 25 years of age was notified.

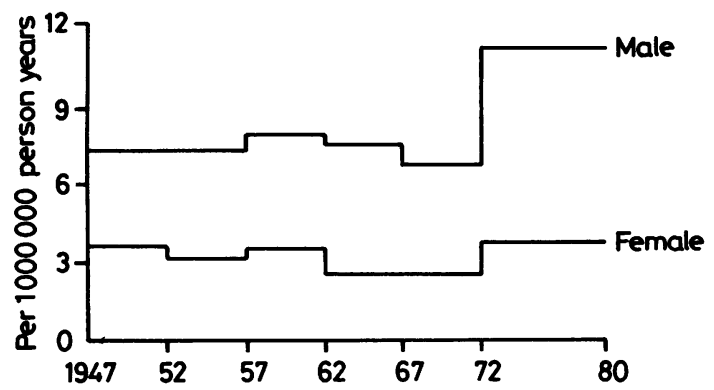

Age-adjusted incidence rates for hypopharyngeal cancer per 1000000 person years. Adjusted to the 1960 population. Material for this figure was provided by the Danish Cancer Registry.
Tobacco and alcohol have been identified as risk factors for cancer of the mouth and pharynx, ${ }^{1,2}$ and it has been shown that liver cirrhosis is more prevalent in hypopharyngeal cancer patients than in other patients. ${ }^{3}$ The purpose of this study is to quantify the effect of combined alcohol and tobacco exposure on the risk of hypopharyngeal cancer.

\section{Materials and methods}

In a case-control study, all newly diagnosed patients with cancer of the hypopharynx or larynx in Denmark during the period March 1980 to March 1982, and under the age of 75 years, were selected as cases. The cancer patients were from five hospital departments involved in therapy. For each case up to four controls were selected from the municipal person registry in which the case was listed. Controls were matched according to sex, residence, and age (born in the same year). The laryngeal cancer study has been described. ${ }^{4-6}$

Both cases and controls received a questionnaire which included questions about occupational exposure as well as consumption of tobacco and alcohol. Information from the medical records of cases was abstracted by nurses collaborating in the project. Only the $\mathbf{3 2}$ hypopharyngeal cancer patients constitute the case group in this study.

Twenty-six of the 32 cases were males: 16 were under 55 years of age, 9 were between 55 and 64, and 7 were between 65 and 74 years.

In a stratified analysis of unmatched data the hypopharyngeal cancer patients are compared with the 
Table 1 Distribution of cases and controls according to age, sex, and consumption of tobacco and alcohol

\begin{tabular}{|c|c|c|c|c|c|}
\hline \multirow[b]{2}{*}{$\begin{array}{l}\text { Age } \\
(y r)\end{array}$} & \multirow[b]{2}{*}{ Sex } & \multirow[b]{2}{*}{ Exposure* } & \multirow[b]{2}{*}{ Cases } & \multicolumn{2}{|l|}{ Control groups } \\
\hline & & & & $\begin{array}{c}\text { Laryngeal } \\
\text { cancerpatients }\end{array}$ & $\begin{array}{c}\text { Population } \\
\text { sampled controls }\end{array}$ \\
\hline \multirow[t]{4}{*}{$\leqslant 60$} & $\mathbf{F}$ & None & 2 & 12 & 59 \\
\hline & & Tobacco & 1 & 11 & 26 \\
\hline & & Alcohol & 0 & 0 & 4 \\
\hline & & Alcohol + tobacco & 1 & 2 & 2 \\
\hline \multirow[t]{4}{*}{$\leqslant 60$} & $\mathbf{M}$ & None & 3 & 32 & 189 \\
\hline & & Tobacco & 5 & 22 & 83 \\
\hline & & Alcohol & 0 & 13 & 64 \\
\hline & & Alcohol + tobacco & 7 & 33 & 70 \\
\hline \multirow[t]{4}{*}{$>60$} & $\mathbf{F}$ & None & 0 & 16 & 61 \\
\hline & & Tobacco & 2 & 6 & 10 \\
\hline & & Alcohol & 0 & 2 & 1 \\
\hline & & Alcohol + tobacco & 0 & 1 & 0 \\
\hline \multirow[t]{4}{*}{$>60$} & $\mathbf{M}$ & None & 5 & 78 & 382 \\
\hline & & Tobacco & 2 & 34 & 95 \\
\hline & & Alcohol & 3 & 25 & 57 \\
\hline & & Alcohol + tobacco & 1 & 34 & 38 \\
\hline
\end{tabular}

* None: Less than $10 \mathrm{~g}$ tobacco daily and less than $150 \mathrm{~g}$ alcohol per week.

Tobacco: $10 \mathrm{~g}$ or more tobacco and less than $150 \mathrm{~g}$ alcohol per week.

Alcohol: Less than $10 \mathrm{~g}$ tobacco daily and $150 \mathrm{~g}$ alcohol or more per week.

laryngeal patients and community sampled controls. The data are presented in table 1 . The "not exposed" reported that they smoked less than $10 \mathrm{~g}$ tobacco daily and drank less than 10 drinks (about $150 \mathrm{~g}$ alcohol) per week as an average consumption over decades. The group "only exposed to tobacco" drank less than 10 drinks per week, and the group "only exposed to alcohol" had a tobacco consumption of less than $10 \mathrm{~g}$ daily. The tobacco content of a cigarette was set at $1 \mathrm{~g}$, a cigar at $3 \mathrm{~g}$, and a pipeful at $2.5 \mathrm{~g}$.

None of the cases refused to participate in the study. Four percent of the laryngeal patients refused, and so did $22 \%$ of the population sampled controls. Out of 128 matched controls 95 participated.

For the statistical analysis the Mantel-Haenszel test was used, ${ }^{7}$ and the test based confidence limits were estimated according to Miettinen. ${ }^{8}$ Analysis of the matched data in table 2 was performed according to the method described in the appendix. This appendix was compiled by JI.

\section{Results}

As shown in table 2, moderate or heavy use of tobacco and alcohol increases the risk of hypopharyngeal cancer compared to risk estimates for the low exposure group. It is seen that the risk of combined exposure to both alcohol and tobacco approximately equals the relative risk for tobacco exposure multiplied by the relative risk for alcohol exposure.

Similar results are found when hypopharyngeal cancer patients are compared only with their matched controls.

Smoking and drinking habits were found to be similar for hypopharyngeal cancer patients and laryngeal cancer patients (table 3 ).
Table 2 Estimated risk ratios of hypopharyngeal cancer associated with the average consumption of alcohol and tobacco (95\% confidence limits in parentheses). Stratified analysis based upon data from table 1 .

\begin{tabular}{llll}
\hline $\begin{array}{l}\text { Control } \\
\text { groups }\end{array}$ & $\begin{array}{l}\text { Tobacco } \\
\text { IOg or more } \\
\text { daily }\end{array}$ & $\begin{array}{l}\text { Alcohol } \\
\text { ISOg or more weekly }\end{array}$ & \\
\cline { 3 - 4 } & & No & Yes \\
\hline All controls & No & 1.0 & $1.7(0.5-5.9)$ \\
(stratified analysis) & Yes & $3.0(1.3-6.9)$ & $5.2(2.0-13.6)$ \\
Only matched controls & $\begin{array}{l}\text { No } \\
\text { Yes }\end{array}$ & 1.0 & $1.6(0.4-6.1)$ \\
& 3.1(1.2-8.5) & $5.1(0.7-25.5)$ \\
\hline
\end{tabular}

Risks are expressed relative to a risk of 1.00 for persons who had a low (or no) consumption of alcohol and tobacco.

Table 3 Exposureodds ratios. Hypopharyngeal cancer patients compared with laryngeal cancer patients $\mathbf{9 5 \%}$ confidence limits in parentheses). Stratified analysis based upon data from table 1 , laryngeal cancer patients as controls.

\begin{tabular}{cll}
\hline $\begin{array}{l}\text { Tobacco } \\
\text { lOg or more daily }\end{array}$ & \multicolumn{2}{l}{ Alcohol, 150g or more weekly } \\
\cline { 2 - 3 } & No & Yes \\
\hline No & 1.0 & $1.1(0.3-4.3)$ \\
Yes & $1.7(0.7-4.3)$ & $1.5(0.5-4.1)$ \\
\hline
\end{tabular}

Odds are expressed relative to a risk of 1.00 for persons who had a low (or no) consumption of alcohol and tobacco.

\section{Discussion}

Tables 2 and 3 indicate that the effect of combined exposure to alcohol and tobacco is greater than the sum of excess risk associated with the two exposures. The results are similar to those found for oral cancers by Rothman and Keller. ${ }^{1}$ However, tables 2 and 3 should be interpreted cautiously. The exposure categories are open-ended, and 
alcohol and tobacco habits are correlated. Part of the apparent interaction between alcohol and tobacco may therefore be due to residual confounding. Unfortunately, the amount of information in the study does not allow a more detailed stratification of the exposure categories. On the other hand, alcohol and smoking habits were found to be similar for the two cancer groups, and the effect of combined exposure to alcohol and tobacco probably follows a multiplicative model, similar to that found for cancer of the larynx. $^{6}$

The smoking and drinking habits of the hypopharyngeal cancer patients can be compared with those of the laryngeal cancer patients without fear of selection bias due to non-respondents, and probably also without fear of information bias. This is not the case when the hypopharyngeal cancer patients are compared with population sampled controls. It is possible that the smoking or drinking habits among the non-respondents are more frequent than in the respondents; this would tend to bias the risk estimates towards high values. It is also possible that the cancer patients underestimate their consumption of alcohol and tobacco more than do the controls. This would tend to bias the risk estimates towards low values. However, the calculated risk estimates are similar to those found by others for oral or laryngeal cancer. Cancer of the hypopharynx resembles cancer of the larynx with regard to the combined effect of drinking and smoking habits, but at a much lower risk level.

We thank the following for their cooperation:

Kirsten Haue-Pedersen, Hanne Lundsgaard Jensen, Meta Thye Pedersen, Inge Kjelstrup, Ulla Fasting, Mathilde Lajer, Bente Bislev, Margrethe Larsen, Birgit Jansen, Karen Kristensen, Karen Margrethe Pedersen, Kirsten Pryds Jensen, Kirsten Bork Nielsen, Hanne Sand Hansen, Birthe Dam Nielsen, and Anni Overdal Poulsen. The study was supported by grants from the Danish Medical Research Council (Nos 12 - 9449, 12 - 2819).

\section{References}

${ }^{1}$ Rothman K, Keller A. The effect of joint exposure to alcohol and tobacco on risk of cancer of the mouth and pharynx. $J$ Chron Dis 1972; 25: 711 - 6 .

${ }^{2}$ Vogler WR, Lloyd JW, Milmore BK. A retrospective study of etiological factors in cancer of the mouth, pharynx, and larynx. Cancer 1962; 15: 246 - 58.

${ }^{3}$ Keller AZ, Terris M. The association of alcohol and tobacco with cancer of the mouth and pharynx. Am J Public Health 1965; 55: 1578 - 85.

${ }^{4}$ Olsen J, Sabroe S, Lajer M Welding and cancer of the larynx: A case-control study. Eur J Cancer Clin Oncol 1984; 20: $639-43$.

${ }^{5}$ Olsen J, Sabroe S. Occupational causes of laryngeal cancer. $J$ Epidemiol Community Health 1984; 38: $117-21$.

${ }^{6}$ Olsen J, Sabroe S, Fasting U. Interaction of alcohol and tobacco as risk factors in cancer of the laryngeal region. J Epidemiol Community Health 1985; 39: 165 - 8.
${ }^{7}$ Mantel N, Haenszel W. Statistical aspects of the analysis of data from retrospective studies of disease. $J N L$ 1959; 22: $719-48$

${ }^{8}$ Miettinen OS. Simple interval estimation of risk ratio. Am J Epidemiol 1974; 100: 515 - 6.

${ }^{9}$ Breslow NE, Day NE. statistical methods in cancer research. Volume 1: The analysis of case-control studies. Lyon: WHO, 1980.

${ }^{10}$ Pike MC, Casagrande J, Smith PG. Statistical analysis of imdividually matched case-control studies in epidemiology: factor under study a discrete variable taking multiple values. Brit J Prev Soc Med 1975; 29: 196 - 201.

\section{Appendix}

\section{CASE/CONTROL MATCHING WITH TWO DETERMINANTS}

We would like to evaluate the effect (relative risk) of two attributes among a group of cases by matching each case with one or more controls, which take important confounding attributes in regard, except the interesting determinants, $A$ and $B$.

For example, cases and controls are matched for age, sex, urbanisation, etc., while the attributes of interest areo consumption of alcohol and tobacco.

Cases are grouped in four subsets $\mathrm{OO}, \mathrm{AO}, \mathrm{OB}$, and $\stackrel{\text { S }}{-}$ $\mathrm{AB}$. For each case-subset the controls are enumerated in similar subsets. The number of controls in each of these 16 . subsets is noted as $C(i, j)$, see below:

\begin{tabular}{lccccc}
\hline $\begin{array}{l}\text { Case- } \\
\text { subsets }\end{array}$ & \multicolumn{2}{l}{ Number ofControls } & & & \\
\cline { 2 - 6 } & $O O$ & $A O$ & $O B$ & $A B$ & \\
\hline OO & $\mathrm{C}(1,1)$ & $\mathrm{C}(1,2)$ & $\mathrm{C}(1,3)$ & $\mathrm{C}(1,4)$ \\
$\mathrm{AO}$ & $\mathrm{C}(2,1)$ & $\mathrm{C}(2,2)$ & $\mathrm{C}(2,3)$ & $\mathrm{C}(2,4)$ \\
$\mathrm{OB}$ & $\mathrm{C}(3,1)$ & $\mathrm{C}(3,2)$ & $\mathrm{C}(3,3)$ & $\mathrm{C}(3,4)$ \\
$\mathrm{AB}$ & $\mathrm{C}(4,1)$ & $\mathrm{C}(4,2)$ & $\mathrm{C}(4,3)$ & $\mathrm{C}(4,4)$ \\
\hline
\end{tabular}

Now, corresponding cells in the extradiagonal part are arranged for logit analysis, while the diagonal sets $(i=j)$ are disregarded. The model for the logit analysis is:

\begin{tabular}{|c|c|c|c|c|}
\hline \multicolumn{3}{|l|}{ Scores } & \multicolumn{2}{|l|}{ Numbers } \\
\hline$x_{A}$ & $\chi_{B}$ & $\chi_{A B}$ & $(i, j)$ & $(j, i)$ \\
\hline 1 & 0 & 0 & $C(A, 0)$ & $\mathrm{C}(\mathrm{O}, \mathrm{A})$ \\
\hline 0 & 1 & 0 & $\mathrm{C}(\mathrm{B}, \mathrm{O})$ & $\mathrm{C}(\mathrm{O}, \mathrm{B})$ \\
\hline 1 & 1 & 1 & $C(A B, O)$ & $\mathrm{C}(\mathrm{O}, \mathrm{AB})$ \\
\hline-1 & 1 & 0 & $\mathrm{C}(\mathrm{B}, \mathrm{A})$ & C $(A, B)$ \\
\hline 0 & 1 & 1 & $\mathrm{C}(\mathrm{AB}, \mathrm{A})$ & $C(A, A B)$ \\
\hline 1 & 0 & 1 & $C(A B, B)$ & $C(B, A B)$ \\
\hline
\end{tabular}

The odds ratio for each line is estimated as

$$
\ln \left(R_{i j}\right)=X_{A} \ln \left(R_{A}\right)+X_{B} \ln \left(R_{B}\right)+X_{A B} \ln \left(R_{A B}\right)
$$

Each set, $\mathrm{C}(\mathrm{i}, \mathrm{j})$, is a vector containing the number of controls of attribute $j$ matched to a case of attribute $i$. They are counted in groups according to the number matched and the number of $\mathrm{j}$-controls in the match. This procedure is similar to that used by Breslow and Day ${ }^{9}$ for analysis of a single attribute in matching with a varying number of controls. The odds ratios are estimated by the MLE 
method. Pike, Casagrande, and Smith ${ }^{10}$ describe the MLE method applied to several attributes, but only with one-to-one matching. They do not consider matching with a varying number of controls.

The program MATAB and its accessory program MATL are used for the rather cumbersome analysis. The program evaluates the combined risks as well as the primary risks, setting all three Rs, two, and one of the Rs equal to 1.0 .

The significance of an individual odds ratio is evaluated by the loss of information, that is, the difference in the likelihood ratio that results from equating the particular odds ratio to 1.0. (Copies of the program in Fortran as well as the data are available from the authors.) 